\title{
Functional Tests Completion Status
}

National Cancer Institute

\section{Source}

National Cancer Institute. Functional Tests Completion Status. NCI Thesaurus. Code C162331.

A term used to describe the state or condition of the completeness of the functional test data. 